\title{
Multimodality neuromonitoring in severe pediatric traumatic brain injury
}

\author{
Adam M.H. Young ${ }^{1}$, Mathew R. Guilfoyle ${ }^{1}$, Joseph Donnelly ${ }^{1}$, Peter Smielewski ${ }^{1}$, Shruti Agarwal ${ }^{2}$, Marek Czosnyka ${ }^{1}$ and \\ Peter J. Hutchinson ${ }^{1}$
}

Each year, the annual hospitalization rates of traumatic brain injury (TBI) in children in the United States are 57.7 per $100 \mathrm{~K}$ in the $<5$ years of age and 23.1 per $100 \mathrm{~K}$ in the $5-14$ years age group. Despite this, little is known about the pathophysiology of $\mathrm{TBI}$ in children and how to manage it most effectively. Historically, TBI management has been guided by clinical examination. This has been assisted progressively by clinical imaging, intracranial pressure (ICP) monitoring, and finally a software that can calculate optimal brain physiology. Multimodality monitoring affords clinicians an early indication of secondary insults to the recovering brain including raised ICP and decreased cerebral perfusion pressure. From variables such as ICP and arterial blood pressure, correlations can be drawn to determine parameters of cerebral autoregulation (pressure reactivity index) and "optimal cerebral perfusion pressure" at which the vasculature is most reactive. More recently, significant advances using both direct and nearinfrared spectroscopy-derived brain oxygenation plus cerebral microdialysis to drive management have been described. Here in, we provide a perspective on the state-of-the-art techniques recently implemented in clinical practice for pediatric TBI.

$\mathbf{T}$ he early management phase of traumatic brain injury (TBI) aims to achieve hemodynamic stability, limit secondary insults (e.g., hypotension, hypoxia), obtain accurate neurological assessment, and appropriately select patients for further investigation (1). The primary brain injury leads to brain edema, elevated intracranial pressure (ICP), and disruption of cerebral autoregulation that can lead to hyperperfusion and worsening edema or hypoperfusion and ischemia. Our understanding of how escalating brain edema leads to an increase in ICP, which, in turn, causes reduction in cerebral perfusion pressure (CPP; mean arterial blood pressure minus ICP), cerebral blood flow (CBF), and oxygenation, has improved greatly over the past few years (2). Moreover, how these changes impact on cellular metabolism in the adult brain has been described through the use of cerebral microdialysis studies $(2,3)$. This selfescalating process is further complicated by the presence of other organ injuries that cause instability of ventilation and circulation. The intensive management of an infant or child with TBI thus involves careful monitoring and manipulation of the factors that affect oxygen delivery to the brain: blood gas tensions, blood pressure, ICP, fluid balance, blood viscosity, and hematocrit; however, there is very little evidence available to direct optimal patient care in children. Optimization and individualization of intensive care after TBI is the goal of multimodality neurologic monitoring.

Detection of secondary events (such as intracranial hypertension, ischemia, worsening edema, excitotoxicity, seizure, or spreading depressions) remains a major target of neuromonitoring and an area of ongoing research. ICP and $\mathrm{CPP}$ are the most widely accepted neuromonitoring parameters and have been shown in many studies to be related to mortality after TBI; however, these studies were specifically adult studies (4-6). More recently, studies in adult patients demonstrated that cerebral autoregulation $(7,8)$ and brain tissue oximetry (9-12) have been linked to outcome after head injury. Although there is no conclusive proof that optimization of these parameters may influence neurological recovery, indirect evidence of better outcomes in adults managed in specialized neurocritical care units $(13,14)$, where tiered therapy is based on neuromonitoring, supports their use, and further exploration of their clinical value within a pediatric cohort. Pineda et al. (15) support the concept that a pediatric neurocritical care programme can improve the outcome in children who sustain a TBI. Direct monitoring of cerebral extracellular chemistry by microdialysis is a promising technique that has enhanced our understanding of the pathophysiology of brain injury and is maturing as a clinical monitor that can be employed in combination with other monitoring methods (such as cerebral oximetry and ICP monitoring) to assist in the management of patients on an individual intention-to-treat basis $(16,17)$. Furthermore, the implications with regards to pediatric studies may be different in the sense that we have no knowledge of the evolution of the inflammatory/metabolic burden in children after injury,

${ }^{1}$ Department of Clinical Neurosciences, Division of Academic Neurosurgery, Addenbrooke's Hospital, University of Cambridge, Cambridge, UK; ${ }^{2}$ Department of Pediatric intensive Care, Addenbrooke's Hospital, University of Cambridge, Cambridge, UK. Correspondence: Adam M.H. Young (ay276@cam.ac.uk)

Received 22 July 2016; accepted 31 August 2017; advance online publication 20 December 2017. doi:10.1038/pr.2017.215 
despite accounting for up to $35 \%$ of head injuries in pediatric patients (18). Non-accidental head injury is more closely linked with repeated injuries to the brain (19). As a result, the pathophysiology of the disease and indeed the treatment of non-accidental TBI is different to single injury, high impact trauma. For these reasons it is excluded from this review as it is regarded as a different mechanism of injury and less frequently are these patients as dependent on high-frequency monitoring.

\section{NEUROIMAGING}

The use of neuroimaging has become increasingly valuable in predicting prognosis in severe pediatric TBI, particularly in the initial hours post ictus (20). Computed tomography (CT) is important for the rapid detection of different types of intracranial injury including extra-axial hemorrhage (e.g., subdural or epidural hematoma), acute hydrocephalus, fractures, or other intracranial lesions that may require acute neurosurgical intervention. The early CT is also useful for triage of patients to detect those who are likely to need neurosurgery, require management in an intensive care unit vs. general hospital setting as well as those who can be safely discharged from the emergency department and managed at home.

It is understood that acute CT imaging is universally performed in the developed world for patients with severe TBI. Two studies $(21,22)$ show that children with severe TBI have a high incidence of intracranial injury on CT scan $(75 \%$ and $62 \%$, respectively). In these studies, intracranial injury included brain contusion, extracerebral hematoma, intracerebral hematoma, diffuse axonal injury, acute brain swelling, penetrating craniocerebral injury, pneumocephalus, subarachnoid hemorrhage, alterations to cisterns, midline shift, or fractures (Figure 1). Neither study included treatment-related outcome data related to the findings on CT scan and thus could not be used as specific evidence for this guideline.

Although CT is always obtained acutely in patients with severe TBI, the use of two or more CT studies is not agreed

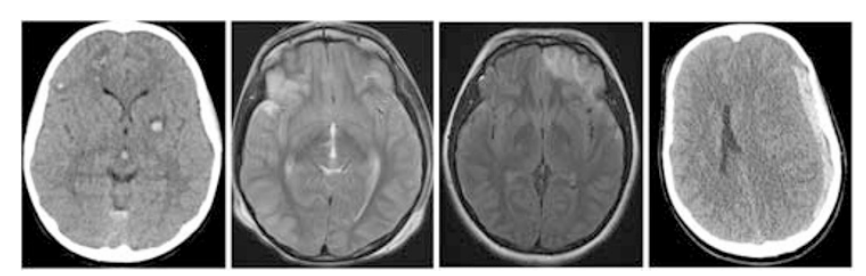

Figure 1. Clinical images of pediatric diffuse axonal injury. (a) Computed tomography (CT) scan of a 7-year-old girl with diffuse axonal injury and widespread petechial hemorrhages and small contusions measuring up to $9 \mathrm{~mm}$ in size. (b) Axial T2 FLAIR magnetic resonance imaging (MRI) demonstrating hyperintensity in the subcortical white matter of the left superior frontal gyrus consistent with small amount of edema. (c) Axial T2 FSE sequence MRI of a 7-year-old girl with hemorrhagic contusions with cortical thickening in the left inferior frontal and anterior temporal lobes. (d) CT scan of of a 9-year-old girl with There is a $15 \mathrm{~mm}$ left to right midline shift and left uncal herniation with effacement of the basal cisterns and compression of the midbrain. on. Repeating a CT scan in children with severe TBI is usually considered when there is (1) no evidence of neurologic improvement; (2) persistent or increasing ICP; or (3) an inability to assess neurologic status (e.g., sedation, paralytic agents) (23). Studies have reported delayed or progressive lesions in 1 to $50 \%$ of adult/pediatric patients with TBI (24). Because epidural hematoma/subdural hematoma requiring surgical intervention can develop hours to days after the acute injury, some investigators have suggested that a follow-up CT scan be routinely acquired at 1-3 days post injury even when clinical deterioration is not evident under the assumption that early diagnosis prompts early intervention leading to a better long-term outcome (25). However, because children with severe TBI are medically unstable and (if portable CT is not available) may further deteriorate during transport to the CT scanner (hemodynamic instability, increased ICP, oxygen desaturation), the decision to order a repeat scan is a treatment decision, weighing the knowledge gained against the risk of additional secondary brain injury. Likewise, because of the long-term effects of CT radiation exposure (lifetime risk of fatal cancer resulting from one head CT in a 1 -year-old child is as high as 1 in 1,500), the neurosurgical decision to order a CT scan also should be considered a treatment decision, weighing the knowledge gained against the risk of long-term radiation exposure (25). This guideline addressed the issue of the value of routinely acquiring repeat CT scans in children with severe TBI.

Although magnetic resonance imaging sensitivity is understood to be superior to CT for intracranial evaluation, it is not as easily obtained acutely after injury and has not been as widely validated in large studies, particularly regarding influence on management decisions. Nevertheless, recent advances in rapid magnetic resonance imaging has demonstrated comparable results to CT $(26,27)$ without the concerns over radiation. In addition, particular sequences can be used to provide correlations with intracranial variables. Specifically, arterial spin labeling can be used to determine CBF in children (28); however, these are only at the stage of preliminary testing and have yet to be brought forward into clinical practice.

\section{INTRACRANIAL PRESSURE}

Multimodality monitoring of cerebral physiology encompasses the application of different monitoring techniques and integration of several measured physiologic and biochemical variables into assessment of brain metabolism, structure, perfusion, and oxygenation status (29). The primary aim of multimodality monitoring is to identify evolving changes in neurophysiology that are detrimental and correct these before permanent deficit occurs (2). Multimodality monitoring issued routinely in adult TBI (30-35) and is beginning to gain momentum in children. Among others, trends in ICP (36) has been identified as a key variable that can separate outcome groups in children.

For over 40 years, significant improvements in both survival and functional outcome after severe TBI have been achieved 
using intensive care management protocols that center on the measurement of ICP and medical and surgical treatment of intracranial hypertension in adult patients (37).

Several studies demonstrate an association between intracranial hypertension and/or systemic hypotension and poor outcome after severe TBI in both adults and children $(34,36,38-40)$. Nevertheless, due to the nature of these trials, the majority being small, single center, observation studies, there has been mixed adoption of guidelines-directed management in the United States and abroad $(41,42)$. It has been reported that in the United Kingdom only 59\% of children presenting with severe TBI underwent ICP monitoring with only half of clinical units caring for such children using monitoring technology $(41,42)$. This becomes even more problematic in infants under the age of 2 years (43). Nevertheless, pediatric ICP monitoring after TBI has been demonstrated to have a beneficial effect. Specifically, ICP monitoring was associated with lower in-hospital mortality (adjusted odds ratio (OR) 0.50; 95\% confidence interval (CI): $0.30-0.85 ; P=0.01$ ) in a multicentered Canadian study (44).

In a pediatric study of 56 severely brain-injured patients (39 of whom had severe TBI), $32 \%$ of children had an initial ICP measurement $>20 \mathrm{~mm} \mathrm{Hg}$, but $50 \%$ had ICP maximum $>20$ but 5 at some point during their intensive care course (45). Intracranial hypertension (ICP > 20 ion () may also be significantly more prevalent in children with severe TBI who do not demonstrate spontaneous motor function (80\%) than those who do (20\%) (46). In another multicenter study the duration of ICP burden was compared between adult and pediatric patients after a TBI (47). Interestingly, it was found that intracranial pressures above $20 \mathrm{~mm} \mathrm{Hg}$ lasting longer than $37 \mathrm{~min}$ in adults were associated with worse outcomes; this was found to be the case in children after $8 \mathrm{~min}$ (47).

These studies suggest that children presenting with severe TBI are at notable risk of intracranial hypertension. No specific markers have been identified that reliably determine the presence or absence of intracranial hypertension without monitoring in this population. Two studies of combined treatment strategies also suggest that improved clinical outcomes are associated with successful control of intracranial hypertension $(48,49)$. A prospective observational study of 100 children with severe TBI treated with varying combinations of hyperventilation, diuretics, cerebrospinal fluid drainage, sedation, pharmacologic paralysis, and barbiturates reported that children whose intracranial hypertension was successfully lowered had better 1-year outcomes than children whose intracranial hypertension was uncontrollable (but worse than those without intracranial hypertension) (49). A retrospective review of a prospectively acquired TBI database showed that reduced survival and worsened outcome in children with severe TBI were associated with intracranial hypertension refractory to treatment rather than peak ICP per se (48). In this study, successful control of intracranial hypertension, irrespective of treatment modality (osmolar

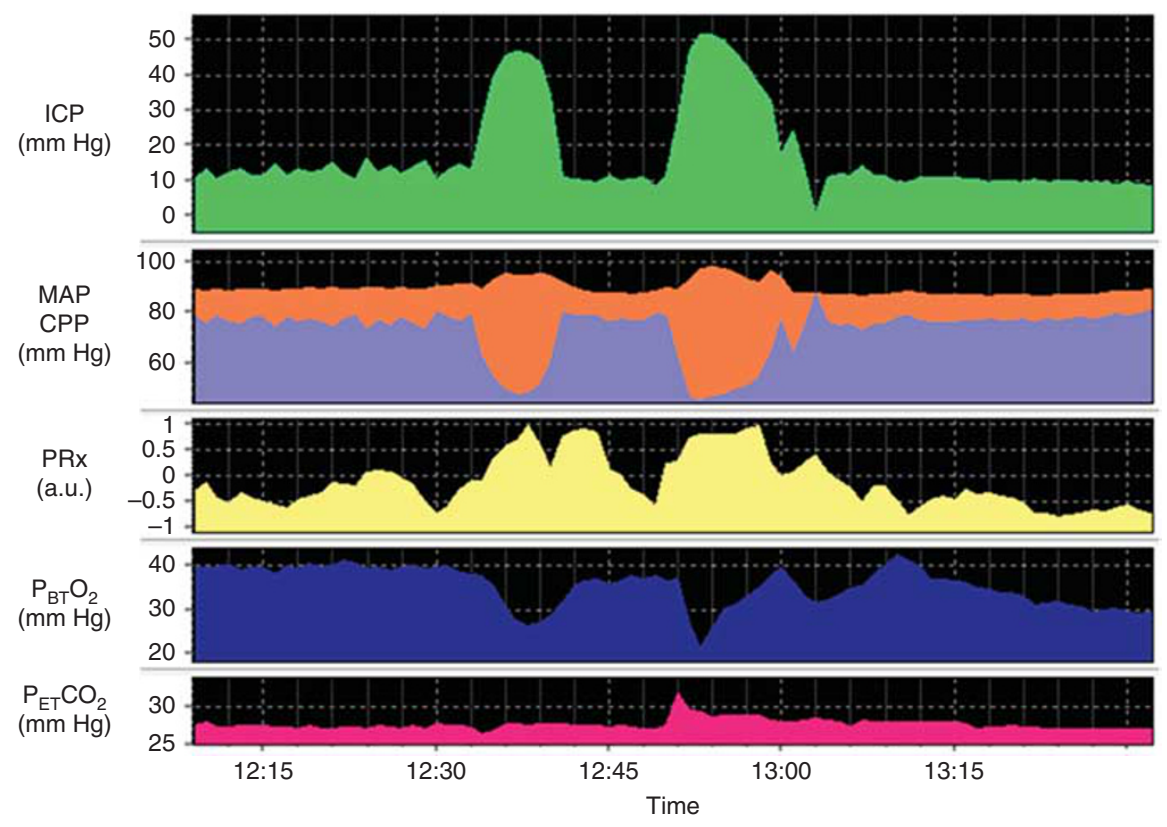

Figure 2. Multimodal monitoring during plateau waves in intracranial pressure (ICP) after traumatic brain injury (TBI). A 9-year-old boy who sustained severe TBI with moderate diffuse axonal injury (Marshall grade 3) on initial computed tomography (CT) scan. During the monitoring on the pediatric intensive care unit, the patient developed rapid and short-lived increases in ICP in a pattern known as intracranial plateau waves. These waves occur in up to a quarter of patients and are thought to be due to vasodilatory cascade in patients with intact vascular pressure reactivity. In the patients, a vasodilatory stimulus (e.g., a decrease in cerebral perfusion pressure (CPP)), increases cerebral blood volume and ICP, further decreasing CPP. This patient demonstrated intact pressure reactivity index (PRx) before the plateau waves (PRx -0.5 a.u.) and during the plateau wave developed both depressed CPP (down to <50u.) Hg), increased ICP ( 50 50u i), decreased brain tissue oxygenation, and impaired PRx. 
therapy, cerebrospinal fluid drainage, decompression, etc.), was deemed to be important.

Although they represent only class III evidence for longterm outcome related to ICP monitoring and are only correlative, these studies support the association of successful ICP monitor-based management of intracranial hypertension with improved survival and neurologic outcome.

The need to prevent raised ICP is recognized as central to current neurocritical care of children after severe TBI. To target this management appropriately, thresholds for ICP treatment are essential. The consensus is that brief increases in ICP that return to normal in $<5$ min may be insignificant; however, sustained increases of $\geq$ in may be insig min likely warrant treatment (50); Figure 2. Pathological and sustained rises in ICP are often referred to as a plateau waves. Plateau waves of ICP are usually identified using the following criteria: (1) an increase of ICP to levels $>40$ 0eate for at least 5 min associated with a significant decrease in CPP and increase in pulse amplitude of ICP; (2) a mean ICP $<255 \mathrm{ss} \mathrm{t}$ in the $30 \mathrm{~min}$ before the start of the plateau wave; and (3) a decrease in ICP below 25 elow in the $30 \mathrm{~min}$ following the plateau wave (51). Plateau waves of ICP are at least as frequent in children as in adult TBI patients (52).

Based in large part on studies in adults, an ICP treatment threshold of 20 ased has been used in most centers for decades. However, the optimal ICP target or targets for pediatric TBI remain to be defined. Normal values for mean arterial blood pressure and hence CPP are lower in children, particularly in infants and young children. It has also been shown in anesthetized children without TBI that the lower CPP limit of autoregulation of CBF is, surprisingly, similar in young children vs. older children-and does not decrease below $\sim 60$ 0prox (53). Thus, young children have less autoregulatory reserve than older children-i.e., the difference in CPP between normal and the lower limit of autoregulation is smaller in infants and young children than it is in older children. This suggests the possible need to set a lower ICP therapeutic target for infants and young children than older children or adults with TBI.

Multiple reports specific to pediatrics support an ICP threshold of 20 an IC $(45,48,54,55)$; however, individual reports do support lower ICP thresholds (as low as 15 howe) (56). However, some pediatric studies suggest higher thresholds (35 or even 40 Howe) (57). Thus, although an ICP threshold of 20 Thus is generally used, and even lower threshold may physiologically make sense for infants and young children, the optimal threshold for ICP-directed therapy and whether or not it should be adjusted for children of different ages deserves additional investigation. It should also be recognized that some of the studies defining the ICP threshold used therapies that are not contemporary, such as aggressive hyperventilation. Finally, in light of the heterogeneity of the pathology and pathophysiology in pediatric TBI, ICP management may need to be individualized in some cases.

\section{CEREBRAL PERFUSION PRESSURE}

$\mathrm{CPP}$, defined as mean arterial pressure (MAP) minus the mean ICP, is the pressure gradient driving blood flow to the brain. In a healthy brain, the CBF is regulated and tightly linked to the metabolic demand for oxygen. In the acutely injured brain decrease in $\mathrm{CBF}$ can result in global or regional cerebral ischemia, potentiating secondary insult.

With the use of continuous multimodality monitoring optimizing CPP is a critical target in the management of acute brain injury. The optimal CPP (CPPopt) threshold and therapeutic approach to achieve it both remain to be defined. Due to the variability in cardiovascular parameters with age and in particular, age-related differences in in MAP, it is assumed that there is a range of CPPopt from infancy to adolescence. There is also a presumption that these targets should be age defined when treating acute brain injury in children.

CPP is relatively simple to calculate, the main technical consideration is the calibration of measurements (Figure 2). For technical accuracy, the MAP and ICP should be zero calibrated at the same level. The microsensor of the ICP monitor is usually placed in the frontal lobe $2-3 \mathrm{~cm}$ within the parenchyma. If using an external ventricular drain, the ICP is calibrated to the level of the foramen of Monro. The MAP pressure on the other hand is classically calibrated to the right atrium; however, some neurocritical care units now advocate the MAP being zeroed to the level of the external acoustic meatus (13). The primary reason for this is that the calculation of CPP will underestimate actual perfusion pressure by an error proportional to the distance between the two calibrated points multiplied by the sine angle of the bed. Usually managed at a bed elevation of $30^{\circ}$, the error range will increase with age and adolescents will have almost doublet error to infants ( 11 vs. 6 The ). In addition to this, the difference between managing an adult patient flat with spinal injuries vs. a $30^{\circ}$ elevation will also double the error (5 vs. 10 nce b) $(58,59)$.

The main reason for undertaking the invasive monitoring required for calculating this number is to titrate treatment using the level of each of the constituent parameters as a guide (i.e., CPP, ICP, and MAP) (59). There is extensive debate on whether management of acute brain injury should be targeted by ICP thresholds, by CPP thresholds, or both. Only a small number of pediatric studies have demonstrated CPP-directed intervention. In two studies, the lower limit of the scale that was used was 40 or bo $(61,62)$, and in two other studies, it was 45 and $(59,60)$. The upper threshold in the scale was 50-70 The . It is evident from these data that low level of CPP will, therefore, also indicate failure to achieve the CPP target as well as a failure to respond to treatment. A consensus from these studies was that CPP $<40$ re $\mathrm{f}$ is associated with poor outcome (59-61). There have been some retrospective studies which have suggested that the CPP should be more aggressive in children with a CPP $<60$ Ther being linked with poor outcome. Nevertheless, there is no evidence in pediatrics to demonstrate that an excessively high CPP has been linked 


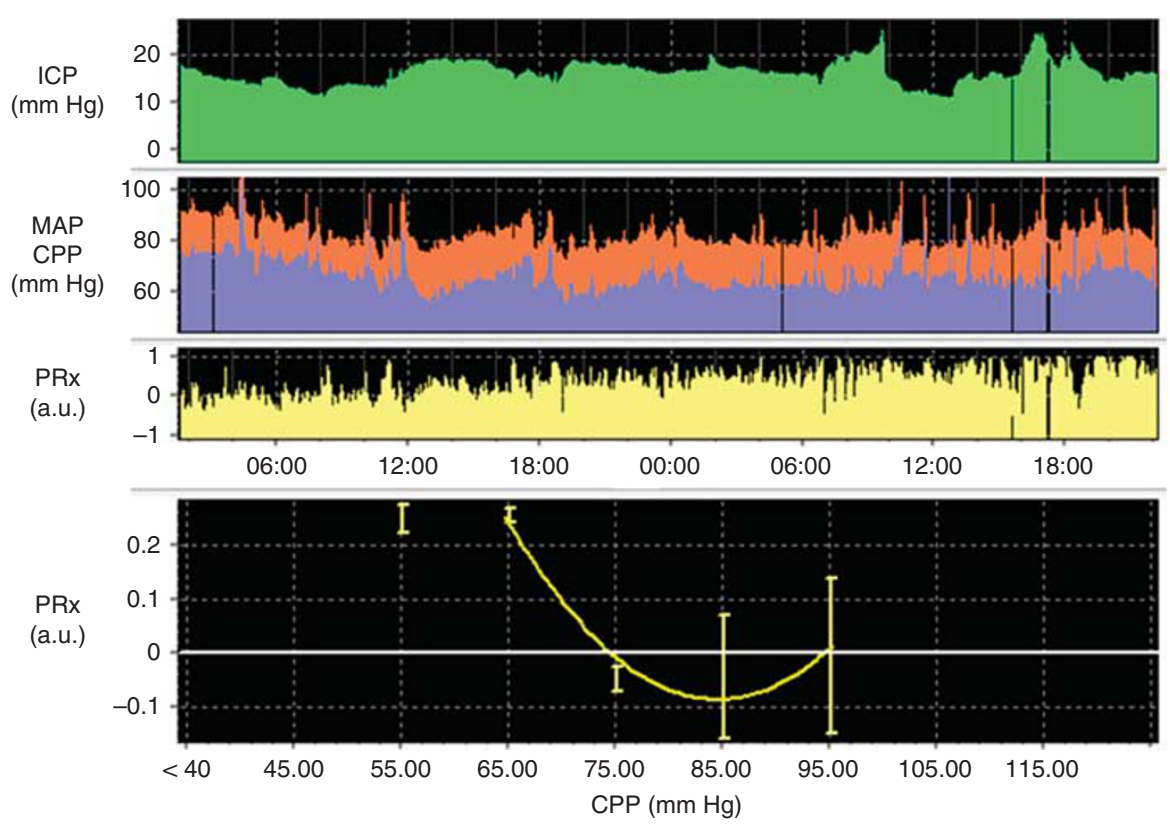

Figure 3. Screenshot from multimodality monitoring after pediatric traumatic brain injury (TBI) depicting deranged pressure reactivity index (PRx) A 11 -year-old boy who presented with diffuse axonal injury (Marshall grade 3) after a road traffic accident. Despite having relatively well-controlled intracranial pressure (ICP) (mean ICP $\sim 15 \mathrm{~mm} \mathrm{Hg}$ ) in the pediatric intensive care unit, this patient had impaired cerebrovascular pressure reactivity as denoted by a PRx approaching +1 towards the end of day 2. Plotting PRx in intervals of cerebral perfusion pressure (CPP) can sometimes reveal a "U-shaped" curve as depicted in the bottom panel; this indicates the CPP at which the brain had the best pressure reactivity may represent a potential therapeutic target. In this case, the mean CPP was 65 ean C, whereas the bottom of the "U-shaped" curve, a theoretical optimal CPP, was 85 theo.

with poor outcome. In adults, the guidelines suggest that aggressive attempts to maintain CPP $>70$ ively with fluids and pressors should be avoided because of the risk of adult respiratory distress syndrome; CPP of $<50$ with should be avoided; and CPP values to target lie within the range of $50-$ 70 et li (59).

What also remains unclear is whether the CPP target is particularly critical over certain time points after injury. Some of the studies report averaging values daily for 5 days (59) and others are averaged over the entire monitoring period when assessed for impact on outcome $(62,63)$. However, this could become important depending on the type of injury, e.g., in those patients who have contusions, during the period when these "blossom" there may be a greater or lesser demand on CPP for the unaffected tissue.

Taken together, caution should be exercised when interpreting the results from the pediatric TBI CPP studies and applying the information to treatment strategies for TBI. As with recommendations for ICP, a large multicenter study with high-resolution data will be required to identify thresholds for pediatric treatment.

\section{CEREBROVASCULAR AUTOREGUATION}

Cerebral autoregulation describes the intrinsic ability of cerebral vasculature to maintain a stable blood flow despite changes in blood pressure or, more accurately, CPP (63). Work in adult patients has demonstrated that $\mathrm{CBF}$ is regulated by changes in cerebrovascular resistance (64-66).
Calculation of autoregulation from CBF at different blood pressure levels using direct perfusion methods is considered to be the best available technique for testing autoregulation; however, its application in a clinical setting is often difficult (67). Cerebrovascular pressure reactivity indicates how ICP changes in relation to changes in MAP and can be assessed using the pressure reactivity index (PRx). PRx is calculated as a moving, linear correlation between slow waves of MAP and ICP, and can be considered an estimator of cerebral autoregulation (7); Figure 3. A negative PRx indicates intact pressure reactivity, whereas a positive PRx indicates impaired pressure reactivity. In children, a deranged PRx has been observed to be closely linked to outcome, particularly mortality $(36,40,68)$. Although only performed in a small number of patients, there have been studies that have indicated that pressure reactivity index has prognostic value and can identify CPP targets that may differ from treatment protocols (68). Most prominently, PRx may be useful for defining age-specific and possibly patient-specific optimal targets for CPP after TBI (40).

Using PRx, a method for finding the CPP at which the vasculature is most reactive has been proposed (68-70). By plotting the average PRx across different ranges of CPP, the CPP with the most negative (or best) PRx can be depicted automatically as a continuous time-dependent variable-the CPPopt (71) (Figure 3).

In adults, patients with a median CPP close to CPPopt were more likely to have a favorable outcome than those in whom median CPP was widely different from CPPopt (71). 


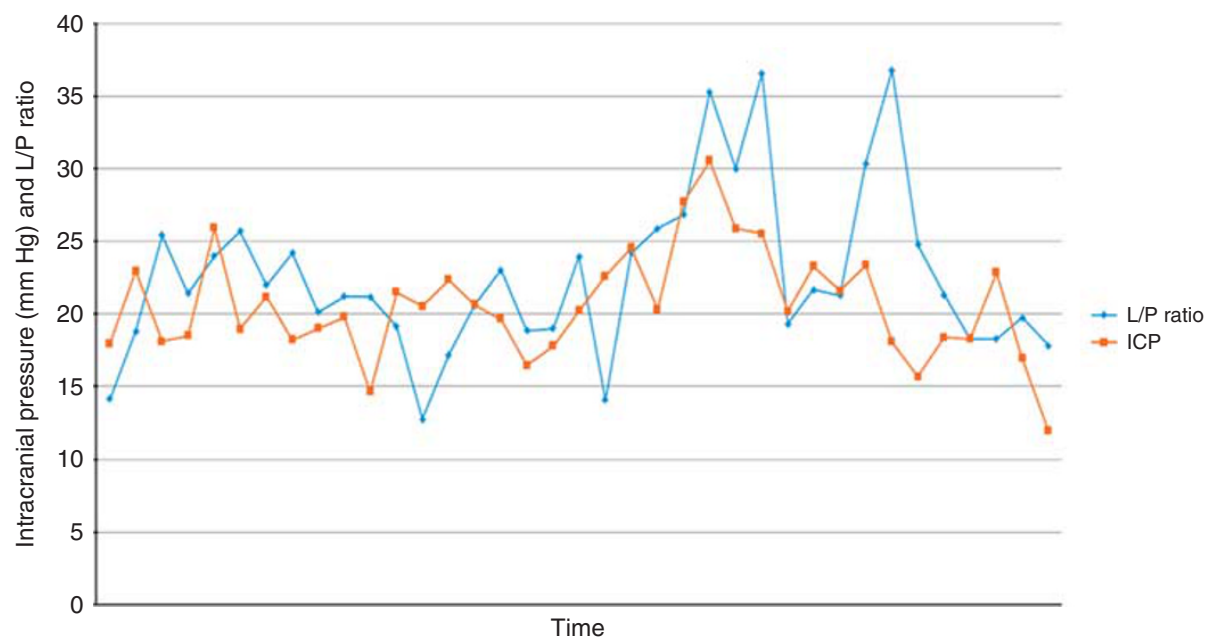

Figure 4. Time line of intracranial pressure (ICP) and microdialysis trace. This is a 7-year-old girl sustained severe traumatic brain injury (TBI) with moderate diffuse axonal injury (Marshall grade 3 ) on initial computed tomography (CT) scan. The timeline points represent 2-h sampling averages. A clear lag of one sampling point can be observed between the measured ICP and the lacate/pyruvate ratio.

Deviations from individualized CPPopt were more predictive of outcome than deviations from a common target CPP (71). This has also been observed in children, although in a significantly smaller cohort $(36,68)$; nevertheless, early consensus suggests that CPP Opt could play a role in optimizing the management of pediatric TBI.

\section{BRAIN OXYGENATION}

Figaji et al. (59) has provided the most extensive study of brain tension oxygenation $\left(\mathrm{PbtO}_{2}\right)$ and long-term outcome in 52 children with severe TBI. $\mathrm{PbtO}_{2}$ was maintained to a threshold of dren with by modulating intracranial pressures. In a cohort with a mortality of $10 \%$, a $\mathrm{PbtO}_{2}<5<5 \mathrm{Pbt}$ for $>1 \mathrm{~h}$ or $<10$ or $<1$ for $>2 \mathrm{~h}$ were associated with a significantly increased risk of unfavorable outcome (Glasgow Outcome Scale and Pediatric Cerebral Performance Category scores) and mortality. This was independent of factors such as ICP, CPP, Glasgow Come Scale, CT classification, and systemic hypoxia. What can be inferred is that in this sample of patients, those with higher $\mathrm{PbtO}_{2}$ and fewer episodes of $\mathrm{PbtO}_{2}<10<10 \mathrm{f}$ had better outcomes. However, it is unclear whether this is a direct response to treatment.

Changes in $\mathrm{PbtO} 2$ in relation to changes in CPP have also been described in small groups of children (Figure 2). Similar parameter were targeted $\left(\mathrm{PbtO}_{2}\right.$ level lar param) (72). Survival was associated with normal initial $\mathrm{PbtO}_{2}$ (Survival ). There was no difference in the mean initial $\mathrm{PbtO}_{2}$ among the 10 survivors and 6 deaths at 3 months. Only six patients had elevated ICP, making the relationship between ICP and $\mathrm{PbtO}_{2}$ difficult to interpret.

An emerging theme from the $\mathrm{PbtO}_{2}$ experience is instructive in general for multimodal monitoring: physiologic responses to TBI are heterogeneous, and interpretation is facilitated by context (73). $\mathrm{PbtO}_{2}$ is poorly correlated with changes in intracranial pressure, although both are associated with outcome. The temporal relationships between $\mathrm{PbtO}_{2}$ and other neuromonitors are dependent on the type of edema, the arterial blood gas tensions, the presence of hyperemic responses, and the metabolic state of the brain tissue interrogated (74).

\section{Extracellular cerebral chemistry}

Direct monitoring of cerebral extracellular chemistry by microdialysis is a promising technique that has enhanced our understanding of the pathophysiology of brain injury. It is maturing as a clinical monitor that can be employed in combination with other monitoring methods (such as cerebral oximetry and ICP monitoring; Figure 4) to assist in the management of adult patients on an individual intention-totreat basis $(15,16)$. The relationship between commonly used microdialysis markers and ratios, and neurological outcome following TBI has been established in adult patients (3). This area of multimodality monitoring is gaining interest in children with a small number of centers in Europe and South Africa adopting the technique. It is hoped that this will complement the current standard of monitoring and improve outcomes.

\section{CONCLUSION}

The evolution of multimodality monitoring techniques has made significant progress over the past 10 years. Currently, a combination of neuroimaging, continuous pressure, cerebral autoregulation, and brain tissue oxygenation monitoring provides a powerful platform to help guide the treatment of these patients. In addition to these techniques, extracellular cerebral chemistry monitoring is gaining interest.

However, there is a risk of overintensifying patients and prolonging intensive care unit care with it is attendant risks balanced against the benefit of providing an optimal and individualized milieu for healing of injured brain tissue. This conundrum has been difficult to resolve with outcome data due to the difficulties studying a critically ill and vulnerable population (75). 
Table 1. Summary table of modalities used to guide the management of TBI

\begin{tabular}{|c|c|c|c|}
\hline Type & What it measures & What it can tell us about physiology & Limitations \\
\hline ICP & $\begin{array}{l}\text { Pressure within the parenchymal or } \\
\text { intraventricular space }\end{array}$ & $\begin{array}{l}\text { Indication of evolving edema, contusions, or } \\
\text { hydocephalus }\end{array}$ & $\begin{array}{l}\text { Intracranial pressure gradients can make } \\
\text { interpretation difficult. Sensors baseline can } \\
\text { drift over time and intraparenchymal sensors } \\
\text { cannot be recalibrated }\end{array}$ \\
\hline CPP & $\begin{array}{l}\text { Estimated pressure perfusing the brain } \\
(\mathrm{CPP}=\mathrm{MAP}-\mathrm{ICP})\end{array}$ & $\begin{array}{l}\text { Warning for brain hypoperfusion or } \\
\text { hyperperfusion }\end{array}$ & $\begin{array}{l}\text { Value depends on zero level for ABP sensor } \\
\text { (heart vs. brain level) }\end{array}$ \\
\hline PRx & $\begin{array}{l}\text { The relationship (correlation) between } \\
\text { spontaneous fluctuations in MAP and } \\
\text { ICP }\end{array}$ & $\begin{array}{l}\text { A positive PRx indicates passive transmission } \\
\text { of } A B P \text { waves to the cerebral circulation- } \\
\text { defective pressure autoregulation. A zero or } \\
\text { negative } P R x \text { indicates intact pressure } \\
\text { autoregulation }\end{array}$ & $\begin{array}{l}\text { Noisy signal. Assumptions that changes in ICP } \\
\text { reflect changes in cerebral blood volume may } \\
\text { not always be valid }\end{array}$ \\
\hline $\mathrm{TCD}$ & $\begin{array}{l}\text { The velocity of red blood cells within } \\
\text { the basal arteries (anterior, middle, and } \\
\text { posterior cerebral arteries) }\end{array}$ & $\begin{array}{l}\text { Global perfusion (hypo- or hyperperfusion). } \\
\text { Vasospasm (abnormally high velocities with } \\
\text { narrowed vessels). Cerebrovascular tone } \\
\text { (using pulse wave form analysis. Cerebral } \\
\text { autoregulation (when combined with ABP } \\
\text { signal) }\end{array}$ & $\begin{array}{l}\text { Cannot evaluate vessel diameter and } \\
\text { therefore cannot assess absolute flow }\end{array}$ \\
\hline NIRS & $\begin{array}{l}\text { The concentration of oxygenated and } \\
\text { deoxygenated hemoglobin in the } \\
\text { tissue underlying the sensor }\end{array}$ & $\begin{array}{l}\text { Local cerebral perfusion (ischemia, } \\
\text { hyperemia) }\end{array}$ & $\begin{array}{l}\text { Unclear extracranial contribution in some } \\
\text { circumstances }\end{array}$ \\
\hline Microdialysis & $\begin{array}{l}\text { Products and substrates of cerebral } \\
\text { metabolism in the interstitial fluid } \\
\text { (lactate, glucose, pyruvate, glutamate, } \\
\text { etc.) }\end{array}$ & $\begin{array}{l}\text { Local cellular metabolism (ischemia, } \\
\text { mitochondrial dysfunction), neuronal damage }\end{array}$ & $\begin{array}{l}\text { Values depend on proximity to intracranial } \\
\text { lesions }\end{array}$ \\
\hline $\mathrm{PBTO}_{2}$ & Brain extracellular oxygen pressure & $\begin{array}{l}\text { Local oxygen availability (ischemia, } \\
\text { hyperemia) }\end{array}$ & $\begin{array}{l}\text { Local measurement that needs to be } \\
\text { interpretted alongside } \mathrm{FIO}_{2} \text { and CPP }\end{array}$ \\
\hline
\end{tabular}

ABP, arterial blood pressure; CPP, cerebral perfusion pressure; $\mathrm{FIO}_{2}$, fraction of inspired oxygen; ICP, intracranial pressure; MAP, mean arterial pressure; NIRS, near-infrared spectroscopy; $\mathrm{PBTO}_{2}$, partial pressure of oxygen in extracellular fluid of the brain; PRx, pressure reactivity index; TBI, traumatic brain injury; TCD, transcranial Doppler.

The overall lack of progress with an evidence-based approach to TBI combined with the divergence of practice that results from a paucity of data has prompted a multicenter relative-efficacy study model, the Approaches and Decisions for Acute Pediatric TBI trial. This approach to large data aggregation and comparison may lead to a better understanding of multimodal monitoring interpretation (76). As such the care of pediatric patients with TBI has never been more comprehensive and, as we hope, can lead to improved outcomes in these patients.

\section{STATEMENT OF FINANCIAL SUPPORT}

We gratefully acknowledge financial support as follows: Research support -the Medical Research Council (MRC, Grant Nos G0600986 ID79068 and G1002277 ID98489) and the National Institute for Health Research Biomedical Research Centre (NIHR BRC) Cambridge (Neuroscience Theme; Brain Injury and Repair Theme). Authors' support-P.J.H.: NIHR Research Professorship, Academy of Medical Sciences/Health Foundation Senior Surgical Scientist Fellowship, and NIHR Cambridge BRC. A.M.H.Y. is supported by an NIHR Academic Clinical Fellowship. J.D. is supported by a Woolf Fisher Scholarship. MC-NIHR BRC.

Disclosure: ICM+ is a software licensed by Cambridge Enterprise. P.S. and M.C. have a financial interest in a part of its licensing fee.

\section{REFERENCES}

1. Kochanek PM, Carney N, Adelson PD, et al. Guidelines for the acute medical management of severe traumatic brain injury in infants, children, and adolescents--second edition. Pediatr Crit Care Med 2012;13 (Suppl 1): S1-82.
2. Hutchinson PJ, Jalloh I, Helmy A, et al. Consensus statement from the 2014 International Microdialysis Forum. Intens Care Med 2015;41: $1517-28$.

3. Timofeev I, Carpenter KL, Nortje J, et al. Cerebral extracellular chemistry and outcome following traumatic brain injury: a microdialysis study of 223 patients. Brain 2011;134 (Part 2): 484-94.

4. Marshall L, Gautille T, Klauber M. The outcome of severe closed head injury. J Neurosurg 1991;75:S28-36.

5. Saul TG, Ducker TB. Intracranial pressure monitoring in patients with severe head injury. Am Surg 1982;48:477-80.

6. Balestreri M, Czosnyka M, Hutchinson $\mathrm{P}$, et al. Impact of intracranial pressure and cerebral perfusion pressure on severe disability and mortality after head injury. Neurocrit Care 2006;4:8-13.

7. Czosnyka M, Smielewski P, Kirkpatrick P, Laing RJ, Menon D, Pickard JD. Continuous assessment of the cerebral vasomotor reactivity in head injury. Neurosurgery 1997;41:11-7.

8. Reinert $\mathrm{M}$, Andres RH, Fuhrer $\mathrm{M}$, et al. Online correlation of spontaneous arterial and intracranial pressure fluctuations in patients with diffuse severe head injury. Neurol Res 2007;29:455-62.

9. van Santbrink H, van den Brink WA, Steyerberg EW, et al. Brain tissue oxygen response in severe traumatic brain injury. Acta Neurochir (Wien) 2003;145:429-38 discussion 438.

10. Valadka AB, Furuya Y, Hlatky R, Robertson CS. Global and regional techniques for monitoring cerebral oxidative metabolism after severe traumatic brain injury. Neurosurg Focus 2000;9:e3 Review.

11. Zauner A, Doppenberg E, Soukup J, et al. Extended neuromonitoring: new therapeutic opportunities? Neurol Res 1998;20 (Suppl 1): S85-90.

12. Carmona Suazo JA, Maas AI, van den Brink WA, et al. $\mathrm{CO}_{2}$ reactivity and brain oxygen pressure monitoring in severe head injury. Crit Care Med 2000;28:3268-74.

13. Patel HC, Menon DK, Tebbs S, et al. Specialist neurocritical care and outcome from head injury. Intensive Care Med 2002;28:547-53. 
14. Patel HC, Bouamra O, Woodford M, et al. Trauma Audit and Research Network. Trends in head injury outcome from 1989 to 2003 and the effect of neurosurgical care: an observational study. Lancet 2005;366:1538-44.

15. Pineda JA, Leonard JR, Mazotas IG, et al. Effect of implementation of a paediatric neurocritical care programme on outcomes after severe traumatic brain injury: a retrospective cohort study. Lancet Neurol 2013;12:45-52.

16. Bellander BM, Cantais E, Enblad P, et al. Consensus meeting on microdialysis in neurointensive care. Intensive Care Med 2004;30:2166-9.

17. Goodman JC, Robertson CS. Microdialysis: is it ready for prime time? Curr Opin Crit Care 2009;15:110-7.

18. US Department of Health and Human Services, AfCaF Administration on Children, Youth, and Families, Children's Bureau, Child Maltreatment, 2010. Accessed 7 February 2014; https://www.acf.hhs.gov/sites/default/ files/cb/cm2014.pdf.

19. Kemp AM, Jaspan T, Griffiths J, et al. Neuroimaging: what neuroradiological features distinguish abusive from non-abusive head trauma? A systematic review. Arch Dis Child 2011;96:1103-12.

20. Tong K, Oyoyo U, Holshouser B. Evidence-based neuroimaging for traumatic brain injury in childrenIn:Medina L, Applegate K, Blackmore Ceds. Evidence-Based Imaging in Pediatrics. New York, NY: Springer, 2010: 85-102.

21. Levi L, Guilburd JN, Linn S, et al. The association between skull fracture, intracranial pathology and outcome in pediatric head injury. $\mathrm{Br} \mathrm{J}$ Neurosurg 1991;5:617-25.

22. Stein SC, Spettell C, Young G, et al. Delayed and progressive brain injury in closed-head trauma: radiological demonstration. Neurosurgery. 1993;32:25-30 discussion 30-31.

23. Hollingworth W, Vavilala MS, Jarvik JG, et al. The use of repeated head computed tomography in pediatric blunt head trauma: factors predicting new and worsening brain injury. Pediatr Crit Care Med 2007;8:348-56.

24. Tabori U, Kornecki A, Sofer S, et al. Repeat computed tomographic scan within 24-48 hours of admission in children with moderate and severe head trauma. Crit Care Med 2000;28:840-4.

25. Brenner D, Elliston C, Hall E, et al. Estimated risks of radiation-induced fatal cancer from pediatric CT. Am J Roentgenol 2001;176:289-96.

26. Young AM, Guilfoyle MR, Donnelly J, et al. Correlating optic nerve sheath diameter with opening intracranial pressure in pediatric traumatic brain injury. Pediatr Res 2017;81:443-7.

27. Roguski M, Morel B, Sweeney M, et al. Magnetic resonance imaging as an alternative to computed tomography in select patients with traumatic brain injury: a retrospective comparison. J Neurosurg Pediatr 2015;15: 529-34.

28. Hu HH, Li Z, Pokorney AL, et al. Assessment of cerebral blood perfusion reserve with acetazolamide using 3D spiral ASL MRI: preliminary experience in pediatric patients. Magn Reson Imag 2017;35:132-40.

29. Wartenberg KE, Schmidt JM, Mayer SA. Multimodality monitoring in neurocritical care. Crit Care Clin 2007;23:507-38.

30. Sykora M, Czosnyka M, Liu X, et al. Autonomic impairment in severe traumatic brain injury: a multimodal neuromonitoring study. Crit Care Med 2016;44:1173-81.

31. Carpenter KL, Czosnyka M, Jalloh I, et al. Systemic, local, and imaging biomarkers of brain injury: more needed, and better use of those already established? Front Neurol 2015: 6-26.

32. Le Roux P, Menon DK, Citerio G, et al. The International Multidisciplinary Consensus Conference on Multimodality Monitoring in Neurocritical Care: Evidentiary Tables: A Statement for Healthcare Professionals from the Neurocritical Care Society and the European Society of Intensive Care Medicine. Neurocrit Care 2014;21 (Suppl 2): S297-361.

33. Liu X, Czosnyka M, Pickard JD, et al. Derangement of cerebral blood flow autoregulation during intracranial pressure plateau waves as detected by time and frequency-based methods. Acta Neurochir Suppl 2016;122:233-8.

34. Chesnut RM, Temkin N, Carney N, et al. Global Neurotrauma Research Group. N Engl J Med 2012;367:2471-81.
35. Czosnyka M, Miller C. Participants in the International Multidisciplinary Consensus Conference on Multimodality Monitoring. Monitoring of Cerebral Autoregulation. Neurocrit Care 2014;21 (Suppl 2): S95-102.

36. Young AM, Donnelly J, Czosnyka M, et al. Continuous multimodality monitoring in children after traumatic brain injury-preliminary experience. PLoS ONE 2016;11:e0148817.

37. Tilford JM, Aitken ME, Anand KJ, et al. Hospitalizations for critically ill children with traumatic brain injuries: a longitudinal analysis. Crit Care Med 2005;33:2074-81.

38. Schoon P, Benito Mori L, Orlandi G, et al. Incidence of intracranial hypertension related to jugular bulb oxygen saturation disturbances in severe traumatic brain injury patients. Acta Neurochir Suppl 2002;81:285-7.

39. Marmarou A, Anderson R, Ward J, et al. Impact of ICP instability and hypotension on outcome in patients with severe head trauma. J Neurosurg 1991;75:S59-66.

40. Brady KM, Shaffner DH, Lee JK, et al. Continuous monitoring of cerebrovascular pressure reactivity after traumatic brain injury in children. Pediatrics 2009;124:e1205-12.

41. Morris KP, Forsyth RJ, Parslow RC, et al. Intracranial pressure complicating severe traumatic brain injury in children: monitoring and management. Intens Care Med 2006;32:1606-12.

42. Segal S, Gallagher AC, Shefler AG, et al. Survey of the use of intracranial pressure monitoring in children in the United Kingdom. Intens Care Med 2001;27:236-9.

43. Keenan HT, Nocera M, Bratton SL. Frequency of intracranial pressure monitoring in infants and young toddlers with traumatic brain injury. Pediatr Crit Care Med 2005;6:537-41.

44. Alali AS, Gomez D, Sathya C, et al. Intracranial pressure monitoring among children with severe traumatic brain injury. J Neurosurg Pediatr 2015;14:1-10.

45. Bruce DA, Raphaely RC, Goldberg AI, et al. Pathophysiology, treatment and outcome following severe head injury in children. Childs Brain 1979;5:174-91.

46. Downard C, Hulka F, Mullins RJ, et al. Relationship of cerebral perfusion pressure and survival in pediatric brain-injured patients. J Trauma 2000;49:654-8 discussion 658-659.

47. Güiza F, Depreitere B, Piper I, et al. Early detection of increased intracranial pressure episodes in traumatic brain injury: External Validation in an Adult and in a Pediatric Cohort. Crit Care Med 2017;45:e316-20.

48. Jagannathan J, Okonkwo DO, Yeoh HK, et al. Long-term outcomes and prognostic factors in pediatric patients with severe traumatic brain injury and elevated intracranial pressure. J Neurosurg Pediatr 2008;2:240-9.

49. Alberico AM, Ward JD, Choi SC, et al. Outcome after severe head injury. Relationship to mass lesions, diffuse injury, and ICP course in pediatric and adult patients. J Neurosurg 1987;67:648-56.

50. McLaughlin MR, Marion DW. Cerebral blood flow and vasoresponsivity within and around cerebral contusions. J Neurosurg 1996;85:871-6.

51. Liu X, Czosnyka M, Pickard JD, Varsos GV, Nasr N, Smielewski P. Derangement of cerebral blood flow autoregulation during intracranial pressure plateau waves as detected by time and frequency-based methods. Acta Neurochir Suppl 2016;122:233-8.

52. Castellani G, Zweifel C, Kim DJ, et al. Plateau waves in head injured patients requiring neurocritical care. Neurocrit Care 2009;11:143-50.

53. Vavilala MS, Lee LA, Lam AM. The lower limit of cerebral autoregulation in children during sevoflurane anesthesia. J Neurosurg Anesthesiol 2003;15:307-12.

54. Pfenninger J, Kaiser G, Lutschg J, et al. Treatment and outcome of the severely head injured child. Intens Care Med 1983;9:13-6.

55. Pfenninger J, Santi A. Severe traumatic brain injury in children-are the results improving? Swiss Med Wkly 2002;132:116-20.

56. Cruz J, Nakayama P, Imamura JH, et al. Cerebral extraction of oxygen and intracranial hypertension in severe, acute, pediatric brain trauma: preliminary novel management strategies. Neurosurgery 2002;50: 774-9 discussion 779-780.

57. Chambers IR, Treadwell L, Mendelow AD. Determination of threshold levels of cerebral perfusion pressure and intracranial pressure in severe 
head injury by using receiver-operating characteristic curves: an observational study in 291 patients. J Neurosurg 2001;94:412-6.

58. Adelson PD, Bratton SL, Carney NA, et al. Guidelines for the acute medical management of severe traumatic brain injury in infants, children, and adolescents. Chapter 7. Intracranial pressure monitoring technology. Pediatr Crit Care Med 2003;4:S28-30.

59. Figaji AA, Zwane E, Thompson C, et al. Brain tissue oxygen tension monitoring in pediatric severe traumatic brain injury. Part 1: relationship with outcome. Childs Nerv Syst 2009;25:1325-33.

60. Kapapa T, Konig K, Pfister U, et al. Head trauma in children, part 2: course and discharge with outcome. J Child Neurol 2010;25: $274-83$.

61. Stiefel MF, Udoetuk JD, Storm PB, et al. Brain tissue oxygen monitoring in pediatric patients with severe traumatic brain injury. J Neurosurg 2006;105:281-6.

62. Narotam PK, Burjonrappa SC, Raynor SC, et al. Cerebral oxygenation in major pediatric trauma: Its relevance to trauma severity and outcome. J Pediatr Surg 2006;41:505-13.

63. Lassen NA. Cerebral blood flow and oxygen consumption in man. Physiol Rev 1959;39:183-238.

64. Fog M. The relationship between the blood pressure and the tonic regulation of the pial arteries. J Neurol Psychiatry 1938;1:187-97.

65. Kontos HA, Wei EP, Navari RM, Levasseur JE, Rosenblum WI, Patterson JL Jr. Responses of cerebral arteries and arterioles to acute hypotension and hypertension. Am J Physiol 1978;234:H371-83.

66. Symon L, Held K, Dorsch NW. A study of regional autoregulation in the cerebral circulation to increased perfusion pressure in normocapnia and hypercapnia. Stroke 1973;4:139-47.

67. Sahuquillo J, Amoros S, Santos A, et al. False autoregulation (pseudoautoregulation) in patients with severe head injury: its importance in CPP management. Acta Neurochir Suppl 2000;76:485-90.
68. Lewis PM, Czosnyka M, Carter BG, et al. Pediatr Crit Care Med 2015;16: 739-49.

69. Steiner LA, Czosnyka M, Piechnik SK, et al. Continuous monitoring of cerebrovascular pressure reactivity allows determination of optimal cerebral perfusion pressure in patients with traumatic brain injury. Crit Care Med 2002;30:733-8.

70. Donnelly J, Aries MJH, Czosnyka M. Further understanding of cerebral autoregulation at the bedside: possible implications for future therapy. Expert Rev Neurother 2015;15:169-85.

71. Aries MJ, Czosnyka M, Budohoski KP, et al. Continuous determination of optimal cerebral perfusion pressure in traumatic brain injury. Crit Care Med 2012;40:2456-63.

72. Figaji AA, Zwane E, Fieggen AG, et al. Pressure autoregulation, intracranial pressure, and brain tissue oxygenation in children with severe traumatic brain injury. J Neurosurg Pediatr 2009;4:420-8.

73. Rohlwink UK, Zwane E, Fieggen AG, Argent AC, le Roux PD, Figaji AA. The relationship between intracranial pressure and brain oxygenation in children with severe traumatic brain injury. Neurosurgery 2012;70: 1220-30 discussion 1231.

74. Budohoski KP, Zweifel C, Kasprowicz M, et al. What comes first? The dynamics of cerebral oxygenation and blood flow in response to changes in arterial pressure and intracranial pressure after head injury. $\mathrm{Br} \mathrm{J}$ Anaesth 2012;108:89-99.

75. Natale JE, Joseph JG, Pretzlaff RK, Silber TJ, Guerguerian AM. Clinical trials in pediatric traumatic brain injury: unique challenges and potential responses. Dev Neurosci 2006;28:276-90.

76. Larsen GY, Schober M, Fabio A, et al. Structure, process, and culture differences of pediatric trauma centers participating in an international comparative effectiveness study of children with severe traumatic brain injury. Neurocrit Care 2016;24:353-60. 